September 2001

\author{
$\mathbf{N}^{\circ}$ 2001-09 \\ Minimum Wage, Exports \\ and Growth \\ PHILIPPE ASKENAZY \\ CNRS and CEPREMAP* \#
}

* Cepremap-ENS, 48 Boulevard Jourdan 75014 Paris, France. E-mail: askenazy@cepremap.ens.fr. Tel: 33143 1362 51; Fax: 33143136259.

\# I am very grateful to Daniel Cohen for his advice. I would like to thank Pierre Cahuc, Harald Uhlig and JeanPierre Laffargue, for helpful criticisms and suggestions; and Alan Manning for providing some of the data sets used in this paper. 


\title{
Minimum wage, exports and growth
}

\begin{abstract}
Using an endogenous growth model in an open economy, we study the impact of minimum wages on growth for an innovator country. We state that a minimum wage shifts efforts from production to $R \& D$, but only in an open economy. Thus, it speeds up long-run growth in proportional to exports. Calibrations suggest the growth surplus can be significant. An empirical study on 11 OECD countries illustrates these results. The impact on welfare is ambiguous because the minimum wage induces unemployment. However, we show that in an open economy, a minimum wage associated with unemployment benefits can pareto dominate laissez faire.
\end{abstract}

JEL Classification: E1, F43, J31.

Keywords: Minimum wage, endogenous growth, welfare, exports.

\section{Salaire minimum, exportations et croissance}

Résumé : A travers un modèle de croissance endogène en économie ouverte, nous étudions l'impact d'un salaire minimum sur la croissance pour un pays innovant. Nous montrons que le salaire minimum, en désavantageant les secteurs faiblement technologiques, induit un transfert de la main d'œuvre qualifiée et des investissements vers la recherche et développement mais uniquement en économie ouverte. Il accélère la croissance proportionnellement au degré d'ouverture. Les calibrations suggèrent que ce surplus de croissance peut dépasser $0.2 \%$ par an pour la France. Une courte étude empirique sur 11 pays de l'OCDE illustre ces propriétés. L'impact sur le bien être est plus ambigu car le salaire minimum provoque mécaniquement du chômage. Néanmoins, nous montrons que sous certaines conditions, notamment un degré d'ouverture suffisant, un salaire minimum en économie ouverte accompagné d'une assurance chômage peut améliorer le bien être des salariés qualifiés comme non qualifiés.

Mots clefs : salaire minimum, croissance endogène, commerce international, bien-être. 


\section{Introduction}

In continental Europe, internationalisation and the minimum wage have often been denounced as a major cause of mass unemployment that has occurred over the last two decades. Minimum wages should exclude low-skilled or young workers (Abowd et al., 2000), create unemployment and thus reduce GPD and welfare. The unemployment can then induce negative scale effect on economic growth, reducing incentives to invest in physical capital (e.g., Daveri et al., 1997,). Blair's decision to re-establish a minimum wage in Great Britain could dramatically increase unemployment.

Nevertheless, these arguments are only relevant if the laissez faire equilibrium is a first best ${ }^{1}$. As Cahuc and Michel (1996) note, many countries use minimum wages and do not seem less efficient. The limitation of the minimum wage can accelerate the increase of inequalities (see Lee (1999) for evidence on the U.S. and Britain). Minimum wages can correct for some inefficiency and therefore can be positive for growth. Cahuc and Michel (1996) study the consequences of minimum wages when there are externalities associated with the accumulation of human capital; Minimum wages create incentives that induce workers to accumulate human capital in order to avoid unemployment. A closed argument is that, in the absence of a minimum wage, the low costs of unskilled labour discourage investment in human capital across education and apprenticeship (Romer, 1989). Acemoglu and Pischke's (1999) theory of general versus specific skills predicts that compressed wage structure induces firms to pay for training. According to Nichell et al. (1997), the only serious argument is that minimum wages tend to raise overall productivity by eliminating low productivity jobs.

In this paper, we assume that unskilled and skilled supplies are fixed in order to exhibit mechanisms unaffected by human capital externalities. We consider the impacts of minimum wages when there are positive externalities in $R \& D$ activities; the firms cannot internalise that their own research contributes to common knowledge. Since Romer (1986), an extensive body of literature shows the theoretical and empirical importance of these externalities. According to Romer [1989], competitive economies experience low ${ }^{2}$

\footnotetext{
${ }^{1}$ See Aghion et al. (1999) for a general survey on growth and income inequality.

${ }^{2}$ This is not necessarily true, Aghion and Howitt (1998) give theoretical cases of competitive economy
} 
and sub-optimal investments in R\&D. If the minimum wage induces higher R\&D efforts, an economy with this imperfection is not necessarily less efficient than the competitive economy.

A minimum wage enlarges the production costs mainly in the more labour-intensive and low-technological industrial branches. Thus, the labour-intensive firms cut employment opportunities. Meanwhile, the skilled employees will leave manufacturing firms for high-tech firms. The minimum wage accelerates industrial modernisation. This factor in turn benefits the research sector, where increasing returns are generated, guaranteeing a higher long-run growth (Romer (1990) and Lucas (1988)).

We will show that this statement is not true in autarky. The inefficiencies associated with minimum wage reduce the market for technological inputs; therefore, they can counterbalance the incentives created by a minimum wage. Nevertheless, we basically argue that in an open economy, the second mechanism is dominated by the "Romer-Lucas" effect because the exterior demand for inputs is not affected by a national minimum wage. It will be shown that the positive impact of the minimum wage on growth is proportional to export. Calibrations suggest that, through this mechanism, the minimum wage can result in significant improvements of long-run growth as large as $0.2 \%$ per annum.

The implications of a minimum wage for welfare are more ambiguous because the minimum wage induces unemployment. However, we will show that the minimum wage associated with unemployment benefits can improve the welfare of all categories of workers. Others policies are more efficient: Direct subsidies to R\&D or taxes on industries intensive in low-skilled workers enable an economy to reach the same growth rate as an economy with minimum wage, without creating unemployment. Actually, our angle is mainly positivist; with a different framework, we support Cahuc and Michel's (1996) conclusion that a decrease in the minimum wage can lower welfare.

This paper proceeds as follows. In part two, we present our model of endogenous growth with a minimum wage in an open economy. Part three studies the impact of the minimum wage on growth and gives the key results. Part four is devoted to a short econometric study on 11 OECD countries. Part five analyses the consequences of mini-

with excessive investments in research. 
mum wages on welfare.

\section{The model}

We consider two countries: North and the rest of the world (the variables for the rest of the world are labelled with a star). We assume perfect capital markets and perfect capital mobility. North is modelled as in Romer (1989); it has two distinct sectors, Research and Development (R\&D) and manufacturing. North is a leader in innovation designing and manufacturing technological and durable inputs. The rest of the world produces consumption goods using northern inputs; but firms with a patent for northern input can manufacture it in the rest of the world.

Labour supplies. Let $N$ be the supply of unskilled workers and $H$ be the number of skilled workers. A minimum wage should influence the share of skilled and unskilled workers in the long run (see Cahuc-Michel, 1996). However, our model is primarily devoted to the exploration of the effects of minimum wages when there are $R \& D$ externalities. Therefore, we assume that $H$ and $N$ are fixed in order to separate the analysis of growth in this framework and the case where there are human capital accumulation externalities. Again, our paper complements Cahuc and Michel (1996).

R\&D. The research sector provides the designs for durable inputs. Let $A$ denote the set of these inputs. The production of new knowledge takes the following continuous functional form provided by Romer (1990):

$$
\dot{A}=\delta H_{A} A
$$

where $H_{A}$ is the number of skilled workers in this sector. Let $w_{H}$ denote their wage. Nevertheless, an infinitely lived patent protects the monopoly of any given new specific product.

Manufacturing. For mathematical tractability, we assume that the production technologies for durable goods and homogenous consumption goods are the same. Let $L$ be the number of low-skilled workers and $H_{Y}$ be that of high-skilled workers in manufacturing. Let $x(a)$ denote the amount of a durable product noted $a$. Let $\alpha+\beta+\gamma=1$; As in 
Romer (1990), the production function in North is

$$
Y=H_{Y}^{\alpha} L^{\beta} \int_{A} x(a)^{\gamma} d a .
$$

According to Wood's (1994) evidence, we assume that the rest of the world has access to the same technology as North. Therefore, the production function has the following form

$$
Y^{*}=T\left(H^{*}, L^{*}\right) \int_{A} x^{*}(a)^{\gamma} d a
$$

where $T\left(H^{*}, L^{*}\right)$ is a function of human capital $H^{*}$ and labour $L^{*}$ in the rest of the world. $T$ can take a very general form. $T^{*}=T^{1 /(1-\gamma)}$ can be interpreted as the scale of the rest of the world.

Market structures. The consumption market and high-skilled worker market are perfectly competitive. The market for durable inputs is under monopolistic competition. Let $p$ be the rental price charged by the firm for the inputs. The demand from northern firms is

$p=\gamma H_{Y}^{\alpha} L^{\beta} x^{\gamma-1}$; for the rest of the world, it is $p=\gamma T\left(H^{*}, L^{*}\right) x^{* \gamma-1}$. Since these two curves exhibit the same constant price elasticity, they can be aggregated $p=E X^{\gamma-1}$, where $X=x+x^{*}$ is the global input demand and the worldwide environment $E=$ $\gamma\left(H_{Y}^{-\alpha^{\prime}} L^{-\beta^{\prime}}+T\left(H^{*}, L^{*}\right)^{1 /(\gamma-1)}\right)^{\gamma-1}, \alpha^{\prime}=\alpha /(\alpha+\beta)$ and $\beta^{\prime}=\beta /(\alpha+\beta)$. The firm chooses a profit-maximizing price, $p$, taking as given the worldwide demand. Because it costs one unit of forgone output to produce one unit of capital, the opportunity cost of one unit of input is the real interest rate $r$. Now, the optimum price is the Chamberlin markup (Tirole, 1988). Let $X$ denote the global demand associated with this price where the profit $\pi$ is $r X(1-\gamma) / \gamma$. The patent cost $P_{A}$ is equal to the present value of the whole stream of profits that the firm, which produces the specific durable input, is able to earn: $P_{A}=\int_{0}^{\infty} \pi(t) e^{-\int_{0}^{t} r(u) d u} d t$. On the balanced growth path, the interest rate $r$ must be constant over time; therefore, in this case:

$$
P_{A}=\frac{X(1-\gamma)}{\gamma}
$$

Remark 1: Firms in the rest of the world must rent northern inputs. Thus, they do not buy it and do not have to contract debt. Therefore, there is no foreign debt, the rents are paid with exports of consumption goods. 
Minimum wage. The unskilled labour market is not perfect. The Northern government imposes a minimum wage (for low-skilled workers). A tractable way (see Cahuc and Michel, 1996) to study the equilibrium consequences of a minimum wage is to consider balanced growth paths with a constant unemployment rate of unskilled workers. Since the supplies of skilled and unskilled labours are fixed, this assumption causes the relative wage structure to be stationary along the stationary growth paths i.e., in our framework, $G=\frac{\alpha w_{L}}{\beta w_{H}}$ the adjusted ratio of unskilled wages $w_{L}$ (equal to the minimum wage by definition) to skilled wages $w_{H}$ is constant along the paths. In the economy with a minimum wage, $G$ is naturally above the competitive wage ratio.

These latter results are also compatible with the French minimum wage (the SMIC). The article L 114-6 of the French labour code states that "the successive rises [of the minimum wage] will tend to eliminate any long-standing distortion between the increase of the minimum wage and the evolution of general economic conditions and incomes." Thus, the partial index-linking of the SMIC to average wages and to inflation, and the regular "coups de pouce" (boosts) maintain the legal minimum wage at approximately half the average wage: the Kaitz index (ratio of minimum wage to average wage) stands between $49 \%$ and $51 \%$ (Dolado et al., 1996). Note that with the Cobb-Douglas specification, $G=\frac{H_{Y}}{L}$. The use of the stationarity of $G$ will reduce the model to linear equations.

Remark 2: The wage of unskilled workers fixed in relation to that of skilled workers can also be interpreted as non-competitive wage differentials resulting from the operation of trade unions or efficiency wages (see Romer (1996) for theory and Krueger and Summers (1988) for evidence).

Finally, we assume that unemployed workers received positive benefits (their value will not affect the growth rate).

The consumers. Consider a household $i \in I$ ( $I$ is finite). Its composition is a continuum of skilled, unskilled, employed or unemployed workers; its changes (e.g. switch from employment to unemployment) are assumed continuous with respect to time ${ }^{3}$. The intertemporal welfare is Ramsey's type: $\int_{0}^{\infty} \frac{c_{i}^{(1-\sigma)}}{1-\sigma} e^{-\rho t} d t$, where $c_{i}$ is the household con-

\footnotetext{
${ }^{3}$ These smoothness hypothesis can be significantly weakened using more sophisticated maximum theorems.
} 
sumption, $\rho$ is the positive preference for present and $\sigma$ the non-negative intertemporal elasticity of substitution. The consumption good is chosen as the numeraire. The households maximize their intertemporal utility under the income constraint: $\dot{d}_{i}=r d_{i}+R_{i}-c_{i}$, where $d_{i}$ represents current household debts and $R_{i}$ is the current household income (wages, unemployment benefits, ...).

The first-order conditions for maximisation yield the classical individual KeynesRamsey rule (see Romer, 1990): $r=\rho+\sigma\left(\dot{c}_{i} / c_{i}\right)$. Therefore, for any household (whatever its composition), $\dot{c}_{i}=(r-\rho) c_{i} / \sigma$. This linear relation is clearly aggregable over all households regardless of their compositions. If $C=\sum_{i} c_{i}$ is the aggregated consumption, we have $\dot{C}=(r-\rho) C / \sigma$ which gives the Keynes-Ramsey rule:

$$
r=\rho+\sigma(\dot{C} / C)
$$

\section{The impact of minimum wage on growth}

Elements of the dynamics can be found in the appendix A. Now we will turn to the stationary growth path. Market equilibrium requires that the wage of high-skilled workers be the same in the $R \& D$ sector and the manufacturing industries, i.e.:

$$
\alpha H_{Y}^{\alpha-1} L^{\beta} A x^{\gamma}=P_{A} \delta A
$$

where $x=\left[r H_{Y}^{-\alpha} L^{-\beta} / \gamma^{2}\right]^{1 /(\gamma-1)}$. Using the $P_{A}$ value from (4), it follows that

$$
r=\Omega\left\{\left(H_{Y}\right)^{\alpha^{\prime}} L^{\beta^{\prime}}+\left[T\left(H^{*}, L^{*}\right)\right]^{1 /(1-\gamma)}\right\}\left(H_{Y} / L\right)^{\beta^{\prime}}
$$

where $\Omega=\gamma(1-\gamma) \delta / \alpha$. On the balanced growth path, the growth must equal the rate of economic technological progress; the Ramsey rule becomes

$r=\rho+\sigma \delta H_{A}$. Eliminating $r$ between these two expressions yields:

$$
\rho+\sigma \delta H_{A}=\Omega\left\{\left(H_{Y}\right)^{\alpha^{\prime}} L^{\beta^{\prime}}+\left[T\left(H^{*}, L^{*}\right)\right]^{1 /(1-\gamma)}\right\}\left(H_{Y} / L\right)^{\beta^{\prime}} .
$$

So, introducing $G$, it holds that:

$$
\rho+\delta \sigma H_{A}=\Omega\left\{H_{Y}+T\left(H^{*}, L^{*}\right)^{\frac{1}{1-\gamma}} G^{\beta^{\prime}}\right\} .
$$


Then

$$
H_{A}=\frac{-\rho+\Omega H}{\Omega+\sigma \delta}+\Omega \frac{T\left(H^{*}, L^{*}\right)^{\frac{1}{1-\gamma}} G^{\beta^{\prime}}}{\Omega+\sigma \delta} .
$$

Let $G_{o}$ denote the corrected ratio of relative wages in a perfect labour market. Let $G_{m}>G_{0}$ denote the value of $G$ resulting from the minimum wage fixed by North. The growth surplus on the balanced trajectories, $\Delta_{s} g$, is consequently:

$$
\Delta_{s} g=\delta \Omega \frac{T\left(H^{*}, L^{*}\right)^{\frac{1}{1-\gamma}}}{\Omega+\sigma \delta}\left(G_{m}^{\beta^{\prime}}-G_{o}^{\beta^{\prime}}\right) .
$$

At the same time, the minimum wage induces low-skilled unemployment in the manufacturing sector. The following paragraphs are devoted to a more precise study of the underlying mechanism in autarky and in an open economy.

Autarky. Let us first consider the case of a closed economy $\left(T\left(H^{*}, L^{*}\right)=0\right)$. The model is simply that of Romer (1990) which holds that

$$
H_{A}=\frac{-\rho+\Omega H}{\Omega+\sigma \delta} .
$$

Therefore, the minimum wage does not change R\&D performances. Thus in our framework, the minimum wage has no effect on equilibrium growth: $\Delta_{s} g=0$. In fact, the "Romer-Lucas" effect holds: the decrease of labour in manufacturing lowers the marginal productivity of skilled workers in this sector. But at the same time, an opposite effect with the same magnitude holds: the demand for durable inputs drops and thus the marginal productivity of skilled workers also falls in $\mathrm{R} \& \mathrm{D}$. The minimum wage reduces inequality as well as output and raises unemployment in the manufacturing sector.

This result is specific to Cobb-Douglas technology. Other specifications can induce either a positive or negative balance for growth (see proposition 1). The Cobb-Douglas case has to be considered as a benchmark.

Open economy. Let us now study the case of an open economy. The two effects, "Romer-Lucas" and "demand", which have been identified for a closed economy, will hold again for an open economy. Yet the symmetry does not hold in an open economy. Indeed, the human capital market is a domestic market (there is no brain drain) whereas the durable input market is a worldwide market. This asymmetry leads to the non-nullity of $\Delta_{s} g$. Because $G_{m}>G_{o}$, the growth surplus due to minimum wage is positive. 
The demand effect is dominated by "Romer-Lucas" incentives. Again, the fall in input demand is curbed by the demand from the rest of the world. The scale of this mechanism increases with $T^{*}$ and the minimum wage. Contrary to the conventional view, a minimum wage is more favourable to growth in an open economy.

Remark 3: More generally, due to remark 2, our result will cause growth to increase when non-competitive wage differentials increase in an open economy. This mechanism adds a complementary line to the complex causality chain between wage inequalities and growth (see Aghion et al., 1999).

Remark 4: Like the growth rate, unemployment is increasing with $T^{*}$ and the minimum wage. We thus have a positive but indirect relationship between unemployment and growth in an open economy. Aghion and Howitt (1998) also find theoretically that higher growth is associated with higher unemployment but as a direct consequence of enhanced creative-destruction (see also Bean and Crafts, 1995). However, these results are not consistent with Daveri and Tabelini (1997) evidence: in Europe, high unemployment seems associated with low growth, supporting the scale effect. Likewise, Van Schaik and de Groot (1997) find a negative relation between unemployment and growth in a twocountry leader-follower model with endogenous growth and dual labour markets (see also remark 6 and de Groot (2000)).

Calibrations. We can calibrate the model. Take the following specifications for the parameters:

$N=5 / 3$ and $H=1 ; \alpha=\beta=\gamma=1 / 3 ;$ "Productivity" of $\mathrm{R} \& \mathrm{D}, \delta=1 / 6$

Preference for present, $\rho=0.05$; Consumer elasticity of substitution, $\sigma=2$

The parameters for the production technology are close to the empirical evidence in Mankiw-Romer-Weil (1990). The productivity of R\&D and the proportion of skilled workers are justified ex post: with these parameters, the model predicts in autarky a $2.3 \%$ growth per annum; and, in a perfect labour market, the ratio ${ }^{3}$ of skilled wages on unskilled wages is 1.73 , and is of the same kind as the ratio of college graduate wages on unskilled wages in the United States in the seventies (before the huge increase in the last two decades). The equation (11) gives the value of $\Delta_{s} g$, given these parameters, $T^{*}$ and 
$G_{m}{ }^{4}$. Assume now that the scale of the rest of the world is $20 \%$ of that of North and that $G_{m}$ is $10 \%$ higher than $G_{0}$; then the equilibrium annual growth rate is $2.60 \%$ while it is $2.55 \%$ without a minimum wage. In this case, through the mechanism of the model, the minimum wage induces a $0.05 \%$ per annum growth bonus. The growth surplus can be significantly larger for higher minimum wage and/or for vaster rest of the world. Table I reports the growth surplus for various values of the minimum wage and of the size of the rest of the world.

Thus, the growth surplus can exceed $0.2 \%$ per year. For example, take $G_{m}=1.2 \times G_{0}$ and the scale of the rest of the world half of that of North; The minimum wage results in a $0.24 \%$ per annum growth improvement, while the unskilled unemployment reaches $18 \%$, a still realistic value for some European countries.

\footnotetext{
${ }^{4} G_{0}$ can be easily computed. In the perfect labour market, $L=N$. Then $G_{0}=H_{Y} / N$, where $H_{Y}$ is given by equation $(8)$ - here the second order equation $3.45-2 H_{Y}-\frac{T^{*}}{(5 / 3)^{1 / 2}} H_{Y}^{\frac{1}{2}}$.
} 
TABLE 1: Calibrated growth surplus due to minimum wage $\Delta_{s} g$ in $\%$ per annum

Scale of the rest of the world relative to North in \%

Wage ratio with

110

\begin{tabular}{|ccccc}
10 & 20 & 30 & 50 & 100 \\
\hline 0.03 & 0.05 & 0.08 & 0.12 & 0.22
\end{tabular}

relative to the ratio for a

120

competitive

labor market in \%

130

0.05

0.10

0.15

0.24

0.43

0.08

0.15

0.22

0.35

0.63 
Generalisation. This subsection is devoted to studying alternative specification of the production function. Consider now that the production function in North is

$$
Y=g_{1}\left(H_{Y}, L\right) A x^{\gamma}
$$

and that of the rest of the world is unchanged.

Summarising the computations of the previous sections, we find that the real interest rate is equal to

$$
r=\delta(1-\gamma) \gamma\left(1+\left(\frac{T}{g_{1}}\right)^{1 /(1-\gamma)}\right) \frac{g_{1}}{\frac{\partial}{\partial H_{Y}} g_{1}} .
$$

Take a general CES specification (Romer (1990]) for $g_{1}$ :

$$
g_{1}\left(H_{Y}, L\right)=\left[\alpha_{1} H_{Y}^{\beta_{1}}+\left(1-\alpha_{1}\right) L^{\beta_{1}}\right]^{(1-\gamma) / \beta_{1}},
$$

with $\beta_{1}<1$. After simplification we find that:

$$
r=\frac{\delta \gamma}{\alpha_{1}}\left(g_{1}^{\frac{1}{1-\gamma}}+T^{\frac{1}{1-\gamma}}\right)\left[\alpha_{1}+\left(1-\alpha_{1}\right)\left(\frac{L}{H_{Y}}\right)^{\beta_{1}}\right]^{\left(\beta_{1}-1\right) / \beta_{1}}=\rho+\sigma \delta H_{A}
$$

Intuitively, if there is a strong substitutability between skilled and unskilled labourers in manufacturing, a minimum wage, increasing the costs of unskilled labour, can induce firms to "over-substitute" low-skilled workers with skilled ones. Thus, the demand for skilled workers in production can be higher; the skilled workers shift from R\&D to production and therefore growth slows down. More precisely, we prove in the appendix B the following proposition:

Proposition 1 We can distinguish 3 cases:

- low substitutability 5 between skilled and unskilled workers (i.e. $\beta_{1}$ is non positive): here a minimum wage speeds up growth in an open economy. This case includes CobbDouglas specification

- perfect substitutability (i.e. $\left.\beta_{1}=1\right)$ : a minimum wage always has a negative effect on growth. The skilled workers substitute for unskilled workers in the manufacturing sector.

- strong substitutability (i.e. $0<\beta_{1}<1$ ): the sign of the effect is indeterminate. It depends on the other parameters. Nevertheless, the more North is open, the more

\footnotetext{
${ }^{5}$ The elasticity of substitution between skilled and unskilled labour is $1 /\left(1-\beta_{1}\right)$.
} 
efficient it is to establish a minimum wage. Let us define $\tilde{G}$ as $\left(\frac{\alpha w_{L}}{(1-\alpha) w_{H}}\right)^{\frac{1}{1-\beta_{1}}}$. If the following sufficient condition holds

$$
T^{*}>H \frac{\beta_{1}}{1-\beta_{1}}\left(\alpha_{1}+\left(1-\alpha_{1}\right) \tilde{G}^{-\beta_{1}}\right)^{\frac{1}{\beta_{1}}}
$$

then the long-run growth is higher with a minimum wage.

Remark 5: According to the definition of $g_{1}$, labour and capital are complements. Hamermesh (1996) argues that skilled labour and capital are complementary but capital is strongly substitutable with unskilled labour. Unfortunately, this form of production technology is difficult to implement in an endogenous growth model. Such a form should nevertheless accentuate the positive Romer-Lucas effect. Indeed, a minimum wage leads to a substitution of labour by capital. The demand for durable inputs from the domestic firms will be higher. The price of the patents and consequently the R\&D efforts will increase.

Remark 6: The model can be also extended by introducing unskilled labour in the production of patents. The scale effect described in de Groot (2000) then plays. Increasing the costs of unskilled labour in research, the minimum wage reduces mechanically the efficiency of research and thus growth compared to the findings in our model.

The positive impact of a minimum wage on growth is not completely robust to general specifications. Nevertheless, an a priori paradoxical result remains: the openness biases its impact toward higher long-run growth.

\section{An illustrative empirical exercice}

The sources and the exact definitions of variables can be found in the appendix $C$.

The aim of this section is to present a short empirical study for OECD, in order to illustrate our theoretical results and give to food for thought. Nickell et al. (1997) discuss the effects of minimum wages on growth: their potential for influencing productivity is not clear because they eliminate low productivity jobs but also increase unemployment among workers who would otherwise fill them. Persson and Tabellini ${ }^{6}(1992,1994]$ report

\footnotetext{
${ }^{6}$ See Bénabou (1996) for a review of 23 empirical studies on the links between inequality and growth.
} 
a negative and significant correlation between growth and income inequality in democratic countries. Nevertheless, there are no studies on the direct impact of a minimum wage on growth. We will use data on the minimum wage computed by Alan Manning (see Dolado et al. (1996) for details). For 15 OECD countries $^{7}$, they give the value of the Kaitz Index (ratio of the minimum wage to the average wage) for various years. These data are not exactly comparable across countries, but we use them for a panel study.

We first regress the annual growth GROWTH (periods 1970-1975, 1975-1980, 19801985, 1985-1990) on the Kaitz index (years 1970, 1975, 1980, 1985). The tests include GDPGAP, the difference in per cent between the initial GDP and GDP of the United States, and the weight of investments in GDP during a given period; according to Levine and Renelt (1992) (see also Barro et al. (1995) for theoretical foundation), these variables are the most robust determinants of growth. We also introduce a dummy for Luxembourg due to its very small scale and the huge weight of its foreign trade. The Kaitz index plays no significant role (column 1, table 2).

Under the Cobb-Douglas technology, we prove in our framework that the stationary growth rate is linear with the cross product of durable exports and the factor $G^{\beta^{\prime}}-G_{0}^{\beta^{\prime}}$ (relation 11). Let Kait $z_{0}$ be the boundary value of the Kaitz index which does not constrain the labour market. We take the Kaitz index in the United States as this benchmark. If we assume that Kaitz - Kait $z_{0}$ is a quantity of order one with respect to Kait $z_{0}$, the growth surplus due to minimum wage should be proportional to exports $\times\left(\right.$ Kaitz - Kait $\left._{0}\right)$.

Test 2 regresses GROWTH on $\Delta$ Kaitz times the exports. As the model predicts, we get a significant positive correlation between growth and this cross product. This result could be the consequence of idiosyncratic particularities of countries or periods. Therefore, we do the same regression with fixed effects for each country (column 3) and for each period (test 4 ). The coefficient associated with $\Delta$ Kaitz $\times$ exports is slightly altered. It remains statistically significant.

\footnotetext{
${ }^{7}$ We limit our sample to ten "homogenous" European countries and the United States.
} 
TABLE 2: Growth and minimum wage

Dependent variable: GROWTH

\begin{tabular}{|c|c|c|c|c|c|}
\hline & 1 & 2 & 3 & 4 & 5 \\
\hline & & & Country effects & Temporal dummies & \\
\hline $\mathrm{C}$ & $\begin{array}{c}7.24^{\mathrm{E}}-02 * * * \\
(3.82)\end{array}$ & $\begin{array}{c}8.18^{\mathrm{E}}-02 * * * \\
(4.55)\end{array}$ & - & - & $\begin{array}{c}8.37^{\mathrm{E}}-02 * * * \\
(4.30)\end{array}$ \\
\hline Kaitz & $\begin{array}{c}1.63^{\mathrm{E}}-02 \\
(0.79)\end{array}$ & - & - & - & - \\
\hline$\Delta$ Kaitz $*$ EX & - & $\begin{array}{c}8.68^{\mathrm{E}}-02 * * * \\
(3.73)\end{array}$ & $\begin{array}{c}7.73^{\mathrm{E}}-02 * * * \\
(3.90)\end{array}$ & $\begin{array}{c}5.84^{\mathrm{E}}-02 * * * \\
(2.76)\end{array}$ & - \\
\hline Kaitz * EX & - & - & - & - & $\begin{array}{c}8.53^{\mathrm{E}}-02^{* *} \\
(2.26)\end{array}$ \\
\hline $\mathrm{R}^{2} \%$ & 27.4 & 41.0 & 61.4 & 58.6 & 34.5 \\
\hline $\begin{array}{l}\text { Number of } \\
\text { observations }\end{array}$ & 41 & 41 & 41 & 41 & 41 \\
\hline
\end{tabular}

The tests include part of investments into GDP, GDPGAP, EX and the dummy for Luxembourg.

Estimation method: OLS heteroskedastic-consistent. The numbers in parenthesis are t-Student. Author's calculus.

$* * *$ statistically significant at $1 \%$ level; ** at $5 \%$. 
The choice of Kaitz $z_{0}$ can be irrelevant. Thus, we split the growth surplus into exports $\times$ Kaitz and exports. Column 5 again shows a positive and significant correlation between growth and the cross-product of exports and the Kaitz index.

Thus, this empirical study seems to support our theoretical results: while the minimum wage in general has no clear effect on growth, its joined action with the exports has a positive impact on growth for developed countries. However, this exercise is a very first stage. The size of the sample is small. The cross-country regressions to search the sources of economic growth are known to be fragile (Levine and Renelt, 1992); other political or institutional variables should be included (Sala-I-Martin, 1997). A necessary more robust analysis oversteps this paper. We advocate for further investigations.

\section{Welfare analyses}

Even when a minimum wage speeds up growth, it can induce dramatic consequences on welfare; indeed, it reduces current GDP and creates unemployment. The letter statement is controversial. Card and Krueger (1995) find that a minimum wage has no significant consequences on employment while Abowd et al. (2000) show a large reduction of youth employment associated with a marginal increase of the minimum wage. In our framework, the minimum wage necessarily induces unemployment.

Before studying the welfare implication of minimum wages, we give a definition and preliminary results.

Definition 1 An economy $A$ pareto dominates an economy $B$ at date $t$ if and only if for any stationary income redistribution between northern workers in case $B$, there exists a stationary income redistribution in case A such that all workers have, at date $t$, a higher intertemporal welfare in economy $A$.

It is necessary to consider the transitory dynamic in order to determine the exact consequence on welfare of an increase or decrease in the minimum wage. Unfortunately, this study leads to extensive computations and requires numerical estimations (see appendix A). Here, our purpose is less ambitious but gives strong insights for welfare analyses; 
we will compare economies with stationary growth rate and the same initial amount of knowledge. We prove in the appendix the following lemma:

Lemma 1 Assume that $A$ and $B$ are along stationary growth paths $g_{A}$ and $g_{B}$ resp.. $A$ pareto dominates $B$ at date $t$ if and only if:

$$
\frac{W_{A}^{1-\sigma}}{(1-\sigma)\left(\rho-(1-\sigma) g_{A}\right)}>\frac{W_{B}^{1-\sigma}}{(1-\sigma)\left(\rho-(1-\sigma) g_{B}\right)},
$$

where $W_{A}$ and $W_{B}$ are the aggregated incomes in northern economies $A$ and $B$ at date $t$. Intuitively, the welfare depends positively on both the current income and the growth rate.

In autarky, unemployment is the only result of the minimum wage. Therefore, it necessarily decreases welfare. In an open economy, the consequence of a minimum wage is more ambiguous. By continuity, if the openness is low and the minimum wage is high, the latter is inefficient. Moreover, if the intertemporal substitution is low, the consequences of unemployment on welfare will dominate the positive impact of the higher growth rate. Thus, a minimum wage will increase welfare only if the intertemporal substitution is quite large and the economy open enough. The next proposition proves this assertion:

Proposition 2 1) If $\sigma \geq 2$, then the competitive economy at long-run equilibrium pareto dominates an economy with minimum wage and the same initial amount of knowledge.

2) If $0 \leq \sigma<\min \left\{1 ; \frac{1-\gamma}{\gamma}\left(\frac{\beta \rho}{\delta \alpha H}-1\right)\right\}$ then, with $\xi=\frac{\Omega H-\rho}{\sigma+\Omega / \delta}+\left\{\frac{1}{\rho}\left(1-\frac{\gamma \sigma}{1+\gamma}\right)-\frac{\beta}{\delta \alpha H}\right\}^{-1}$, there exists $\bar{T}$

$$
\bar{T}=\left[\frac{\rho}{\Omega}-H+\left(\frac{1}{\delta}+\frac{\sigma}{\Omega}\right) \xi\right] \frac{N^{\beta^{\prime}}}{\Omega[H-\xi / \delta]^{\beta^{\prime}}}
$$

such that, if $T^{*}>\bar{T}$, then an economy with a minimum wage at long-run equilibrium pareto dominates a competitive economy with the same initial amount of knowledge.

The main result is the following: an economy with minimum wage can pareto dominate the competitive economy if the externalities in $R \& D$ are strong enough and the economy is open enough. Recall that human capital is fixed, so our argument complements that of Cahuc and Michel (1996). Moreover, we show that rising internationalisation and minimum wages are not necessarily incompatible: their joined action can both improve growth rate and welfare. 
Nevertheless, it is obvious that, in our model, a minimum wage is not an optimal policy because unemployment induces loss of welfare. Consider subsidies to R\&D and a perfect labour market. The government taxes workers and finances a part $\phi$ of the R\&D investments (i.e. wages of researchers). The equation (10) becomes:

$$
\rho+\delta \sigma H_{A}=\Omega\left(H_{Y}+T\left(\frac{H_{Y}}{N}\right)^{\beta^{\prime}}\right)(1+\phi)
$$

or

$$
(\rho+\sigma g)\left(H-\frac{g}{\sigma}+T\left(\frac{H}{N}-\frac{g}{\sigma N}\right)^{\beta^{\prime}}\right)^{-1}=\Omega(1+\phi)
$$

The growth rate $g$ increases with $\phi$ and any possible value $(g<\delta H)$ can be reached when $\phi$ is large enough. Therefore R\&D subsidies can correct distortions in R\&D as minimum wages does, but without creating unemployment. The same argument applies for direct taxes to production in North. Note, however, that these more efficient policies increase wage inequalities.

\section{Conclusion}

Even if the analysis of externalities associated with human capital accumulation can exhibit a positive impact of minimum wages on growth, the conventional view remains that a minimum wage damages flexibility and competitiveness; it induces unemployment and thus reduces growth. These consequences will be all the more dramatic in a situation of internationalisation. This paper aims to challenge this wisdom. Using a standard endogenous growth model, we have studied the combined effects of openness and minimum wage in an open developed country. The latter has a manufacturing sector which employs lowskilled workers and a R\&D sector which designs durable inputs. We state that if skilled and unskilled labourers are not overly substituted in manufacturing, then a minimum wage can improve growth only if the economy is open. Basically our argument is that a minimum wage disadvantages mainly the manufacturing sector. Admittedly, the domestic demand for technical inputs shrinks, but $R \& D$ is less affected by the consequences of the minimum wage than is manufacturing because the foreign demand for inputs remains stable. Therefore, in an open economy, compared to the case of perfect labour 
markets, the skilled workers shift from production to R\&D; thus, the research effort and the technological growth rate are higher. Calibrations support that, through this channel, the minimum wage can result in significant -beyond $0.2 \%$ per annum- improvements of long-run growth. The more open a country's economy, the more the minimum wage speeds up growth. Empirical evidence on 11 OECD countries illustrates these theoretical results. The implications of minimum wages on welfare are more questionable because unemployment rises. Nevertheless, an economy with minimum wage can pareto dominate the competitive economy if it is open enough. 


\section{Appendix A: dynamics of the model and simulations}

The technology is Cobb-Douglas. Recall that the dynamic is not the result of a central planner program. Let $c=\left(C+C^{*}\right) / A$ denote the global consumption "deflated" by the technical progress. After extensive computations (available upon request to the author), it yields a system of three differential equations of order one on the variables: $X, c$ and $P_{A}$. The capital is the only state variable. Consumption and the price of the patents are controls and can jump. The phase diagram is composed by cones, two of which $\left(\dot{P}_{A}>0, \dot{c}>0, \dot{X}>0\right)$ and $\left(\dot{P}_{A}<0, \dot{c}<0\right.$, $\dot{X}<0)$ are convergent.

Suppose now that at date 0-, the northern economy is in equilibrium and at date 0, a new country (for example an NIC) is instantly integrated into the global economy. Assume $G$ to be constant. In the long run, the demand for inputs and $P_{A}$ are higher; therefore, the economy will be beyond $0+$ on a trajectory in the cone $\left(\dot{X}>0, \dot{c}>0, \dot{P}_{A}>0\right)$. After trade opens, there is a delocalisation of manufacturing production to the rest of the world. The forecast for profits in $R \& D$ is enhanced because the global demand for durable inputs increases. Consequently, $R \& D$ efforts and technological growth instantly rise.

Simulations can be conducted with DYNARE software for the resolution of dynamics models with forward-looking variables ${ }^{8}$. Using the specifications given in the main text, we simulate the model for various values of the openness $T$ between 0 and 1 , and various values of $G$ between 0.58 and 0.8. The half-life of the dynamics of $g$ is shortened by less than two years. Therefore, we can consider that the stationary growth path holds in medium-run. With the value $\sigma=2$, a minimum wage is always a pareto inefficient policy (see section 5 for definition). However, if e.g. $\sigma=1 / 4$ and $T>1 / 4$, then the minimum wage policy pareto dominates laissez-faire.

\footnotetext{
${ }^{8}$ See for a description, Michel Juillard, "Dynare", Couverture Orange CEPREMAP 9602, 1996.
} 


\section{Appendix B}

Proof of proposition 1: With the notations of section 3, the ratio of unskilled workers versus skilled workers wages is

$$
\frac{w_{L}}{w_{H}}=\frac{1-\alpha}{\alpha}\left(\frac{H_{Y}}{L}\right)^{-\beta+1} .
$$

$\tilde{G}$ increases with the minimum wage (i.e. the wage of unskilled workers). If $\beta$ is negative then the equation (16) can be written as:

$$
\left(H_{Y} f_{1}(\tilde{G})+\nu\right) f_{2}(\tilde{G})=\rho+\sigma \delta\left(H-H_{Y}\right)
$$

where $f_{1}$ and $f_{2}$ increase with $\tilde{G}$ and $\nu$ is positive. Consequently, $d H_{Y} / d \tilde{G}<0$ and $d g / d \tilde{G}>0$. More generally, the equation (19) becomes:

$$
\rho+\sigma \delta\left(H-H_{Y}\right)=\frac{\delta \gamma}{\alpha_{1}}\left[H_{Y}\left(\alpha_{1}+\left(1-\alpha_{1}\right) \tilde{G}^{-\beta_{1}}\right)+T^{\frac{1}{1-\gamma}}\left(\alpha_{1}+\left(1-\alpha_{1}\right) \tilde{G}^{-\beta_{1}}\right)^{\frac{\beta_{1}-1}{\beta_{1}}}\right] .
$$

After differentiation,

$$
\begin{gathered}
-d H_{Y}\left[\sigma \delta+\frac{\delta \gamma}{\alpha_{1}}\left(\alpha_{1}+\left(1-\alpha_{1}\right) \tilde{G}^{-\beta_{1}}\right)\right] \\
=d \tilde{G}\left[-H_{Y}\left(1-\alpha_{1}\right) \beta_{1} \tilde{G}^{-\beta_{1}-1}+T^{\frac{1}{1-\gamma}}\left(1-\beta_{1}\right)\left(1-\alpha_{1}\right) \tilde{G}^{-\beta_{1}-1}\left(\alpha_{1}+\left(1-\alpha_{1}\right) \tilde{G}^{-\beta_{1}}\right)^{-1 / \beta_{1}} .\right.
\end{gathered}
$$

Since $d g>0$ iff $d H_{Y}<0$, one has $d g / d \tilde{G}>0$ if

$$
T>\left[H_{Y} \frac{\beta_{1}}{1-\beta_{1}}\left(\alpha_{1}+\left(1-\alpha_{1}\right) \tilde{G}^{-\beta_{1}}\right)^{\frac{1}{\beta_{1}}}\right]^{1-\gamma} .
$$

$H_{Y}$ is endogenous, but we know that $H_{Y}<H$; so if

$$
T^{*}>\left[H \frac{\beta_{1}}{1-\beta_{1}}\left(\alpha_{1}+\left(1-\alpha_{1}\right) \tilde{G}^{-\beta_{1}}\right)^{\frac{1}{\beta_{1}}}\right]
$$

then $\frac{d g}{d \widetilde{G}}$ is positive. This is always true if $\beta_{1}$ is negative.

Proof of lemma 1: Let $\left(Z,\left\{x_{m}^{Z}\right\}\right)$ denote an economy $\mathrm{Z}$ with the stationary allocation $\left\{x_{m}^{Z}\right\}$. If $\left(A,\left\{x_{m}^{A}\right\}\right)$ pareto dominates $\left(B,\left\{x_{m}^{B}\right\}\right)$ then

$$
\int_{0}^{+\infty} \frac{e^{-\rho t}}{1-\sigma}\left(x_{m}^{A} W_{A} e^{g_{A} t}\right)^{1-\sigma} d t \geq \int_{0}^{+\infty} \frac{e^{-\rho t}}{1-\sigma}\left(x_{m}^{B} W_{B} e^{g_{B} t}\right)^{1-\sigma} d t
$$

This relation is equivalent to

$$
\frac{\left(x_{m}^{A} W_{A}\right)^{1-\sigma}}{(1-\sigma)\left(\rho-(1-\sigma) g_{A}\right)} \geq \frac{\left(x_{m}^{B} W_{B}\right)^{1-\sigma}}{(1-\sigma)\left(\rho-(1-\sigma) g_{B}\right)},
$$


or

$$
\frac{\left(x_{m}^{A} W_{A}\right)}{\left.\left[\rho-(1-\sigma) g_{A}\right)\right]^{\frac{1}{1-\sigma}}} \geq \frac{\left(x_{m}^{B} W_{B}\right)}{\left.\left[\rho-(1-\sigma) g_{B}\right)\right]^{\frac{1}{1-\sigma}}}
$$

The aggregation of the last linear relation gives the necessary condition

$$
\frac{W_{A}^{1-\sigma}}{(1-\sigma)\left(\rho-(1-\sigma) g_{A}\right)} \geq \frac{W_{B}^{1-\sigma}}{(1-\sigma)\left(\rho-(1-\sigma) g_{B}\right)}
$$

Now it is obvious that if $(20)$ is verified then $\left(A,\left\{x_{m}^{B}\right\}\right)$ pareto dominates $\left(A,\left\{x_{m}^{A}\right\}\right)$. Q.E.D.

Proof of proposition 2: Assume $T^{*}$ given. Lemma 1 implies that welfare increases with $G$ if and only if

$$
\Phi=\frac{W}{[\rho-(1-\sigma) g)]^{\frac{1}{1-\sigma}}}
$$

increases with $G$. But $W=A\left(\frac{r}{\gamma^{2}}\right)^{\frac{\gamma}{\gamma-1}} G^{-\beta^{\prime}}\left(\alpha H+\beta H_{Y}\right)$ and $\Omega T^{*} G^{\beta^{\prime}}=\rho+\sigma g-\Omega(H-g / \delta)$ therefore $\Phi$ is proportional to

$$
\Phi^{\prime}=\frac{A_{0}(\rho+\sigma g)^{-\gamma^{\prime}}((\alpha+\beta) H-g \beta / \delta)}{[\rho-(1-\sigma) g)]^{\frac{1}{1-\sigma}}(\rho+\sigma g-\Omega H+\Omega g / \delta)},
$$

where $A_{0}$ is the initial stock of knowledge and $\gamma^{\prime}=\gamma /(1-\gamma)$.

Since $g$ increases with $G$, it holds that $d \Phi / d G>0$ iff $d \ln \Phi^{\prime} / d g>0$, with

$$
\frac{d \ln \Phi^{\prime}}{d g}=\frac{-\gamma^{\prime} \sigma}{\rho+\sigma g}-\frac{\sigma+\Omega / \delta}{\rho-\Omega H+g\left(\sigma+\frac{\Omega}{\delta}\right)}-\frac{\beta / \delta}{(\alpha+\beta) H-\beta g / \delta}+\frac{1}{\rho-g(1-\sigma)} .
$$

Note that the last term is the only positive term and that $-\frac{\sigma+\Omega / \delta}{\rho-\Omega H+g(\sigma+\Omega / \delta)}=-\frac{1}{g-g_{a}}$, where $g_{a}$ is the growth rate in autarky.

1. Assume $\sigma \geq 2$ i.e. $-(1-\sigma) \geq 1$. We have $-\frac{1}{g-g_{a}}+\frac{1}{\rho-g(1-\sigma)}<0$ therefore $d \ln \Phi^{\prime} / d g<0$ and $d \Phi / d G<0$ for any $G$ over the clearing market value. The first part of proposition 2 is proved.

2. Assume now $0<\sigma<1$. We have $\frac{1}{\rho-g(1-\sigma)}>\frac{1}{\rho},-\frac{\beta / \delta}{(\alpha+\beta) H-\beta g / \delta}>-\frac{\beta}{\delta \alpha H}$, because $g<\delta H$, and $\frac{-\gamma^{\prime} \sigma}{\rho+\sigma g}>\frac{-\gamma^{\prime} \sigma}{\rho}$. Thus,

$$
\frac{d \ln \Phi^{\prime}}{d g}>\frac{1}{\rho}-\frac{\beta}{\delta \alpha H}-\frac{\gamma^{\prime} \sigma}{\rho}-\frac{1}{g-g_{a}}
$$

If $g>\xi$ then $\frac{d \ln \Phi^{\prime}}{d g}>0$. Recall that $g$ increases with $G$ for $T^{*}$ fixed. Therefore if $g_{0}$ the growth rate of the economy without minimum wage is over $\xi$, then for all $G, \frac{d \ln \Phi^{\prime}}{d g}>0$ i.e. the minimum wage improves welfare. Now relation (9) gives that

$$
\rho+\sigma g_{0}=\Omega\left(H-\frac{g_{0}}{\delta}+\left[\frac{1}{N}\left(H-\frac{g_{0}}{\delta}\right)\right]^{\beta^{\prime}} T^{*}\right),
$$


therefore, if $T^{*}>\bar{T}$, then the minimum wage improves welfare and proposition 2.2 follows.

\section{Appendix C: data used in section 4.}

- Source : R. J. Barro and J. Lee, "Data Set for a Panel of 138 Countries", January 1994;

R. Summers and A. Heston, "The Penn World Table" (Mark 5.6).

Data used: GROWTHx = GRSH5x, growth of real GNP; Exx, part of exports in the GNP.

INVx, part of investments in the GDP; GDPSHxx, GDP per capita;

GDPGAPxx $=[\text { GDPSH(United States)xx - GDPSHxx }]^{*}$ 100/GDPSH(United States).

- Source: Alan Manning's data on the Kaitz index for 15 developed countries.

We use data on Austria, Belgium, Denmark, France, West-Germany, Italy, Luxembourg, Netherlands, Sweden, Great Britain, and the United States. 


\section{REFERENCES}

Abowd J.M., K. Kramarz, T. Lemieux and D.N. Margolis, 2000, Minimum Wages and Youth Employment in France and the United States, in: D.G. Blanchflower and R.B. Freeman eds., Youth Employment and Joblessness in Advanced Countries (NBER, Cambridge) 427-472.

Acemoglu D. and J. S. Pischke, 1999, The structure of wages and investment in general training. Journal of Political Economy 107 (3), 539-572.

Aghion P., E. Caroli and C. Garcia-Penalosa, 1999, Inequality and Economic Growth: The Perspective of the New Growth Theories. Journal of Economic Literature 37(4), 1615-60.

Aghion P. and P. Howitt, 1998, Endogenous Growth Theory (MIT Press, Cambridge).

Barro R.J. and X. Sala-I-Martin, 1995, Economic Growth (McGraw-Hill, New York).

Bean C.R. and N. Crafts, 1995, British Economic Growth since 1945: Relative Economic Decline... and Renaissance?, CEPR Discussion Paper 1092.

Bénabou R., 1996, Inequality and Growth, in: B.S.Bernanke and J.J. Rotemberg eds., NBER macroeconomics annual 1996 (MIT Press, Cambridge and London) 11-74.

Cahuc P. and P. Michel, 1996, Minimum wage, unemployment and growth. European Economic Review 40, 1463-1482.

Card D. and A. Krueger, 1995, Myth and Measurement: The New Economics of the Minimum Wage, (Princeton, Princeton University Press).

Daveri F. and G. Tabellini, 1997, Unemployment, Growth and Taxation in Industrial Countries, CEPR Discussion Paper 1681.

Dolado J., F. Kramarz, S. Machin, A. Manning, D. Margolis and C. Teulings, 1996, The economic impact of minimum wages in Europe, Economic Policy 23, 319-372.

Freeam R.B., and L.F. Katz, 1995, Differences and Changes in Wage Structures (UCP Press, Chicago).

de Groot H.L.F., 2000, Growth, Unemployment and Deindustrialisation (Edward Elgar, London).

Hamermesh A., 1996, Labor Demand (Princeton University Press, Princeton).

Krueger A.B. and L.H. Summers, 1988, Efficiency Wages and Inter-Industry Wage Structure. Econometrica 56, 259-293

Lee D.S., 1999, Wage Inequality in the United States during the 1980s: Rising Dispersion or Falling Minimum Wage, Quarterly Journal of Economics 114(3), 977-1023.

Levine R. and D. Renelt, 1992, A Sensitivity Analysis of Cross-Country Growth Regressions, American Economic Review 82, 942-963.

Lucas R., 1988. On the Mechanics of Economic Development, Journal of Monetary Economics 21, 342.

Nichell S. and R. Layard, 1997, The Labour Market Consequences of Technical and Structural Change, Discussion Paper Series Oxford University 23. 
Machin S. and A. Manning, 1996, Employment and the introduction of a minimum wage in Britain, The Economic Journal 106, 667-676

Mankiw G., D. Romer and D.N. Weil, 1992, A Contribution to the Empirics of Economic Growth, Quarterly Journal of Economics 107, 407-437.

Persson T. and G. Tabellini, 1992, Growth, Distribution and Politics, European Economic Review 33, 593-602.

Person T. and G. Tabellini, 1994, Is Inequality Harmful for Growth, American Economic Review 84, 600-621.

Riviera-Batiz L.A. and P.M. Romer, 1991, International trade with endogenous technical change, European Economic Review 35, 971-1004.

Romer D., 1996, Advanced Macroeconomics (McGraw-Hill, New York).

Romer P.M., 1987, Crazy Explanations for the Productivity Slowdown, in: S. Fischer ed., NBER macroeconomics annual (MIT Press, Cambridge) 163-202.

Romer P.M., 1989, Human Capital and Growth: Theory and Evidence, NBER Working Paper 3173.

Romer P.M., 1990, Capital, Labor and Productivity, Brookings Papers on Economic Activity: Microeconomics, 337-367.

Sala-i-Martin X., 1997, I Just Ran Two Million Regressions, American-Economic-Review 87 (2), $178-83$.

Tirole J., 1988, The Theory of Industrial Organization, (MIT Press, Cambridge).

Van Schaik A.B. and H.L.F. de Groot, 1997, Productivity and Unemployment in a Two-Country Model with Endogenous Growth, CenTER Discussion Paper 9753.

Wood A., 1994, North-South Trade, Employment and Inequality. Changing fortunes in a skill-Driven World (IDS Development Studies Series, Clarendon Press, Oxford). 